\title{
NIVELES DE SELECTIVIDAD TERRITORIAL DE LOS DESTINOS TURÍSTICOS EN MÉXICO
}

\author{
Enrique Propin Frejomil \\ Álvaro Sánchez Crispín \\ Ilia Alvarado Sizzo \\ Universidad Nacional Autónoma de México
}

\section{RESUMEN}

El aumento de los destinos turísticos en México ha significado una diversificación de la oferta turística del país. Sin embargo, la actuación de agentes sociales diversos ha priorizado lugares que destacan notoriamente de los restantes. Este trabajo revela una clasificación de destinos turísticos en diez niveles de selectividad territorial. Para ello, se precisaron las posiciones conceptuales asumidas; se reconocieron acontecimientos ligados con el fomento turístico-territorial, se formuló la metodología seguida y se describieron rasgos típicos de la jerarquía resultante de lugares.

Palabras clave: Selectividad territorial, destinos turísticos, México

\section{Levels of territorial selectivity of tourist destinations in Mexico}

\begin{abstract}
The diversification of the tourist market in Mexico has resulted in a growing number of destinations, some of which have been given special attention by different social agents. This paper proposes a classification of Mexican tourist destinations arranged into ten categories of territorial selectivity. Firstly, we portray the conceptual framework for this research, then we indicate the evolution of the territorial sponsorship of tourism in Mexico; further on, we make clear the methodological path followed and, finally, we explain the fundamentals of each category of tourist destinations found.
\end{abstract}

Keywords: Territorial selectivity, tourist destinations, Mexico.

Recibido: 9 de septiembre de 2015

Devuelto para su revisión: 10 de febrero de 2016

Aceptado: 26 de abril de 2016

Departamento de Geografía Económica. Instituto de Geografía. Universidad Nacional Autónoma de México. Circuito Exterior s/n. Ciudad Universitaria. C. P. 04510. Delegación Coyoacán, CIUDAD DE MÉXICO (México).E-mail: propinfrejomil@igg.unam.mx,asc@igg.unam.mx, ialvarado@igg.unam.mx 


\section{INTRODUCCIÓN}

La localización geográfica de los destinos turísticos en México ha estado influida por intereses de agentes sociales diversos; esta concurrencia de voluntades de grupos nacionales y de capitales foráneos ha variado en el tiempo en lo que concierne a la selección de los territorios; los cambios en la orientación regional de la política nacional del turismo han propiciado el aumento de los lugares con funciones turísticas; algunos de los nuevos espacios seleccionados han sido habilitados en forma exclusiva y promocionados con interés especial.

El patrón reconocido de "sol y playa", que primó y concentró la imagen turística del país desde los años cincuenta del siglo pasado, marca, en el decenio de los setentas, la creación de destinos turísticos de primera importancia internacional por la presencia de grupos hoteleros de relevancia mundial y la afluencia de turistas de poder adquisitivo alto; ese fue el contexto de creación de los denominados Centros Integralmente Planeados que, aún en el presente, continúan encabezando los lugares con actividad turística en México (Propin y Sánchez, 2007).

El escenario geográfico ha cambiado a partir de los diez últimos años; a pesar de que sigue prevaleciendo el carácter atractivo de las playas para el turismo doméstico e internacional, el gobierno federal y, por correspondencia, la Secretaría de Turismo han redirigido la atención hacia el aprovechamiento de otros recursos turísticos; en este sentido, reconocen la conveniencia de “... impulsar la innovación de la oferta y elevar la competitividad del sector [y] posicionar a México como un destino atractivo en segmentos poco desarrollados, como el turismo cultural, ecoturismo y aventura, salud, deportes, de lujo, de negocios y reuniones, y religioso..." (SECTUR, 2013).

Esta nueva perspectiva geográfico-turística se refleja en las estadísticas territoriales recientes emanadas por la Secretaría aludida; de los 56 destinos registrados años atrás (Propin y Sánchez, op. cit), en la actualidad aumentan a 86, que evidencian diferencias funcionales acentuadas; junto a los centros turísticos grandes, por capacidad de alojamiento y afluencia de turistas, emergen otros menores que, sin embargo, atestiguan su selectividad territorial ya sea por la exclusividad del tipo de hoteles, la predominancia de turistas extranjeros o la coincidencia espacial de ambos sucesos. En este orden de ideas, este trabajo se traza como objetivo revelar, a través de una gradación jerárquica, el carácter selectivo y heterogéneo de los destinos turísticos del territorio mexicano mediante atributos indicativos de los actores vinculados con la planificación turística y de la afluencia de los turistas extranjeros.

\section{POSICIONES COGNOSCITIVAS}

La selección, como acción humana individual y social, se asocia con fundamentos teóricos esenciales de la Geografía en lo que concierne a la localización de las actividades humanas. Las decisiones del "dónde" desarrollar, invertir o fomentar un tipo de economía demanda, como requerimiento necesario, la selección de los lugares mediante criterios diversos como las condiciones naturales propicias para el desarrollo de una actividad o 
la proximidad de centros económicos que incentiven su funcionamiento. Hoy en día, los intereses de agentes sociales nacionales y foráneos, se entretejen y resuelven la capitalización de lugares emergentes (Propin, 2003).

En este escenario, se sitúa la expresión conceptual de selectividad territorial; se liga, en su definición, con la acción de seleccionar que remite a la idea de acción y efecto de elegir a una o varias personas o cosas entre otras, separándolas del resto y prefiriéndolas (Real Academia Española, 2014). Esta acepción, en el campo territorial del turismo, precisa de dos consideraciones. Por una parte, la selección de los nuevos lugares está condicionada por la presencia de los destinos turísticos ya existentes, ya sea porque se conciba como parte de su área de influencia regional para fortalecerlo mediante la diversificación de su oferta y, con ello, el aumento de la estadía y derrama del turista, o porque exista el interés en crear núcleos turísticos nuevos que funjan, en el mediano plazo, como centros de importancia nacional e internacional. Por otro lado, la idea de preferencia comúnmente se identifica con las percepciones y decisiones de los turistas (Reig y Coender, 2002); asimismo, se reconoce que las preferencias manifiestas «... influyen en los patrones se selección de los turistas y en las decisiones finales de los visitantes» (Alexandros y Jafary, 2005; Propin y Sánchez, op. cit.; Tran y Ralston, 2005).

La selección del lugar, realizada por gobiernos, instituciones o turistas, está presente en la actividad turística con independencia del paradigma de desarrollo turístico imperante; tanto en la etapa primigenia del surgimiento del turismo, cuando la oferta de los recursos turísticos de los lugares regulaba la demanda, como en la actual, donde ésta influye en la diversificación e inventiva de la oferta (Capece, 2008). En este sentido, la selección de territorios representa el requisito concreto del "dónde" concretar las voluntades y decisiones humanas; se revela como plataforma de partida del consumo del lugar por los turistas (Rakić y Chambers, 2012).

Furtado et al (2012) posiciona la selectividad como parte de la relación turismoterritorio; la acción selectiva depara en la conformación funcional del territorio turístico que emerge. En esta perspectiva, con base en diversos autores, la misma fuente señala tres factores relacionados con la selectividad espacial del turismo: los turistas, el mercado y los planificadores y promotores territoriales; se señala, en lo referente al tiempo de ocurrencia, que: «... Cierta selectividad espacial orienta la elección del turismo, de determinados puntos del territorio, en cada momento histórico» (Ibid.: 1378); las políticas territoriales de los gobiernos sucesivos marcan patrones regionales tendientes, de acuerdo con sus intereses, a la especialización o diversificación de tipos y lugares turísticos.

El proceso de selectividad territorial de los destinos puede ser aprehendido, en el tiempo, a través de dos momentos secuenciales:

En primer término, acontece la noción económica de la selectividad territorial que aparece asociada con los tipos de intervención de las políticas públicas locales y regionales focalizadas hacia las capacidades competitivas de los lugares (Silva, 2005); en esta perspectiva, se induce a «...privilegiar criterios de selectividad territorial mediante la valorización de un número limitado de lugares dotados de factores estratégicos para la expansión y competitividad de sus empresas» (Ibid.: 82) y se reconoce que « ... A partir de la ostensible selectividad territorial del capital global se impone un nuevo mapa 
de regiones ganadoras y perdedoras, donde sólo los espacios mejor dotados participan del nuevo dinamismo de la acumulación» (Ciccolella, 1999; 2006); el carácter selectivo de los lugares turísticos yace, en primera instancia, en la concreción de intereses del capital, nacional y foráneo, vinculado con el sector; las acciones pactadas entre agentes gubernamentales, grupos hoteleros internacionales, operadores turísticos y empresas de transportación convergen en la selección de un lugar que comienza a estructurar su territorio en función del turismo.

El escenario de selectividad territorial primigenia es seguido por el de posicionamiento del lugar en los mercados turísticos nacionales e internacionales que depara, finalmente, en los turistas; los propios agentes sociales, involucrados en su nacimiento, se encargan de dirigir campañas promocionales intencionales; las guías turísticas impresas y los medios digitales disponibles pueden acrecentar las ventajas de selección de los lugares que divulgan y, al mismo tiempo, discriminan «...lo visitable de lo no visitable, lo consumible de lo no consumible» (Schweitzer, 2012: 183); en particular, se puntualiza que las guías «... toman en cuenta las recomendaciones de sus lectores, lo que implicaría el reforzamiento de las asimetrías del mercado y la subordinación de la evaluación de los lugares de destino a los criterios de un redactor fugaz y de un editor lejano» (Ibid.: 183). La selección inducida, en forma consciente o no, también se da en la visualización de los ranking mundiales (por ejemplo los Top Ten) de lugares, hoteles e islas, abundantes en internet. Estas plataformas, que contienen información "indiscutible" e imágenes "atrayentes" poseen una capacidad de convencimiento que puede influir sobre las decisiones de los turistas en sus planes de viaje; este escenario de jerarquías turísticas acontece como parte del contexto actual de «...guerras entre lugares desatadas por la selectividad e inteligencia del capital...» (Gómez, 2010: 139).

Este proceso, en la práctica social, aunque no común, puede invertirse. En México, han existido lugares seleccionados espontáneamente por turistas nacionales o extranjeros debido a sus recursos naturales o culturales. Los propios visitantes marcan el lugar mediante la divulgación que ellos mismos hacen y sus estadías recurrentes; este hecho, que ha detonado la posterior intervención de los agentes turísticos gubernamentales y privados, se patentiza en destinos actuales de las modalidades de sol-playa o de turismo cultural-patrimonial y religioso.

\section{SELECTIVIDAD TERRITORIAL EN LA POLÍTICA TURÍSTICA MEXICANA}

El interés gubernamental por el turismo en México se remonta a los inicios del siglo $\mathrm{XX}$; en esos años, se crean estructuras administrativas que adquieren, con el tiempo, mayor relevancia institucional (Tabla 1). Casi desde sus inicios, los documentos oficiales emitidos mostraron lugares seleccionados para impulsar el turismo; en 1937, se delimitó el país en quince zonas, consideradas en su momento, como de "interés turístico"; fue el primer escenario donde se perfiló y promovió la oferta turística mexicana ligada con «... los centros arqueológicos, coloniales, típicos, industriales, hidrominerales, climáticos y los lugares de bellezas naturales» (DO, 1937: 3). 


\section{Tabla 1 \\ MÉXICO: ACONTECIMIENTOS GUBERNAMENTALES Y JURÍDICOS RELEVANTES RELACIONADOS CON LA EVOLUCIÓN DEL TURISMO}

\begin{tabular}{|c|c|c|c|}
\hline Año & $\begin{array}{l}\text { Acontecimientos } \\
\text { seleccionados }\end{array}$ & \multicolumn{2}{|c|}{$\begin{array}{c}\text { Status institucional / } \\
\text { Dependencia gubernamental }\end{array}$} \\
\hline 1928 & Primera estructura gubernamental para atender la actividad turística. & \multicolumn{2}{|c|}{$\begin{array}{l}\text { Comisión Mixta Pro-Turismo / } \\
\text { Secretaría de Gobernación }\end{array}$} \\
\hline 1930 & $\begin{array}{l}\text { Creciente importancia económico-social de la actividad turística; primer dato } \\
\text { de estadísticas de turismo; registro de } 102820 \text { turistas (1929-1930). }\end{array}$ & \multicolumn{2}{|c|}{$\begin{array}{l}\text { Comisión Nacional de Turismo / } \\
\text { Secretaría de Gobernación }\end{array}$} \\
\hline 1933 & $\begin{array}{l}\text { Se involucran empresas particulares; se crean dos organismos nuevos: el } \\
\text { Comité Oficial y el Patronato de Turismo. }\end{array}$ & \multicolumn{2}{|c|}{$\begin{array}{l}\text { Departamento de Turismo / } \\
\text { Secretaría de Economía Nacional }\end{array}$} \\
\hline 1936 & $\begin{array}{l}\text { Restructuración institucional; las funciones turísticas pasan a ser atendidas } \\
\text { por la dirección General de Población. }\end{array}$ & \multicolumn{2}{|c|}{$\begin{array}{l}\text { Comisión Nacional de Turismo / } \\
\text { Secretaría de Gobernación }\end{array}$} \\
\hline 1937 & Zonificación del país en 15 regiones de interés turístico. & \multirow{8}{*}{\multicolumn{2}{|c|}{$\begin{array}{l}\text { Departamento de Turismo / } \\
\text { Secretaría de Gobernación }\end{array}$}} \\
\hline 1939 & $\begin{array}{l}\text { Participación de México en el I Congreso Interamericano de Turismo en San } \\
\text { Francisco, Estados Unidos; se crean el Consejo Nacional de Turismo y la } \\
\text { Asociación Mexicana de Turismo; registro de } 139000 \text { turistas. }\end{array}$ & & \\
\hline 1941 & $\begin{array}{l}\text { Ávila Camacho (presidente) declara al turismo como una fuente de } \\
\text { ingresos económicos; se pone énfasis en la publicidad turística; se abren } 4 \\
\text { delegaciones en el extranjero. }\end{array}$ & & \\
\hline 1946 & $\begin{array}{l}\text { Miguel Alemán (presidente) reconoce la importancia económica del turismo } \\
\text { en el documento nombrado como "Carta turística" o "Declaración turística". }\end{array}$ & & \\
\hline 1949 & Promulgación de la Ley Federal de Turismo. & & \\
\hline 1951 & $\begin{array}{l}\text { Ruiz Cortínez, presidente en turno, se considera como el primero en valorar } \\
\text { las repercusiones sociales del turismo; enfatiza la autenticidad de la historia } \\
\text { mexicana como atributo singular para el turismo. }\end{array}$ & & \\
\hline 1953 & Celebración del I congreso de Turismo Interior. & & \\
\hline 1956 & $\begin{array}{l}\text { Creación del Fondo de Garantía y Fomento al Turismo (FOGATUR) para } \\
\text { impulsar proyectos ligados con el incremento del turismo. }\end{array}$ & & \\
\hline 1958 & $\begin{array}{l}\text { Definición de atribuciones del nuevo Departamento. El presidente Adolfo } \\
\text { López Mateo continúa apoyando el desarrollo interno de turismo y su } \\
\text { promoción internacional. }\end{array}$ & \multirow[t]{6}{*}{$\begin{array}{l}\text { Departamento } \\
\text { Autónomo } \\
\text { de Turismo }\end{array}$} & \multirow[t]{5}{*}{$\begin{array}{l}\text { Ejecutivo } \\
\text { Federal }\end{array}$} \\
\hline 1959 & $\begin{array}{l}\text { Publicación de un Decreto que contiene los lugares y poblaciones nacionales } \\
\text { de interés turístico. }\end{array}$ & & \\
\hline 1960 & $\begin{array}{l}\text { Comienzo del inventario de recursos turísticos que llevaría al Primer Plan } \\
\text { Nacional de Turismo. }\end{array}$ & & \\
\hline 1961 & $\begin{array}{l}\text { Publicación de la Ley Federal de Turismo; se crea el Consejo Nacional de } \\
\text { Turismo; surgimiento del turismo masivo hacia los destinos de sol, playa } \\
\text { y mar. }\end{array}$ & & \\
\hline 1962 & $\begin{array}{l}\text { Creación del Instituto Mexicano de Investigaciones Turísticas dependiente } \\
\text { del Consejo Nacional y otras secretarías gubernamentales. }\end{array}$ & & \\
\hline 1963 & Promulgación del Primer Plan Nacional de Desarrollo Turístico en México. & & $\begin{array}{l}\text { Oficina de la } \\
\text { Presidencia }\end{array}$ \\
\hline
\end{tabular}




\begin{tabular}{|c|c|c|}
\hline 1974 & $\begin{array}{l}\text { Publicación de la Ley Federal de Fomento al Turismo: se crea la Secretaría } \\
\text { de Turismo; se reciben mayores recursos presupuestales destinados a la } \\
\text { planeación y desarrollo de la actividad turística. }\end{array}$ & Secretaría de Turismo (SECTUR) \\
\hline 1977 & Creación del Fondo Nacional de Fomento al Turismo (FONATUR). & \\
\hline 1984 & Creación de la Subsecretaría de Promoción y Fomento. & \\
\hline 1989 & $\begin{array}{l}\text { Se oficializa la operación de trece Representaciones de Turismo en el } \\
\text { Extranjero. }\end{array}$ & \\
\hline 1999 & $\begin{array}{l}\text { Constitución del Consejo de Promoción Turística de México (CPTM) como } \\
\text { empresa de participación estatal mayoritaria. }\end{array}$ & \\
\hline 2001 & $\begin{array}{l}\text { La SECTUR transfirió al CPTM la planeación y operación del Tianguis } \\
\text { Turístico, principal evento de comercialización de la oferta turística del país; } \\
\text { asimismo, se creó el Programa de Pueblos Mágicos. }\end{array}$ & \\
\hline 2002 & Creación de la Coordinación de Oficinas en el Exterior como parte del CPTM. & \\
\hline 2013 & $\begin{array}{l}\text { Creación de cinco delegaciones regionales de turismo: Noreste, Noroeste, } \\
\text { Centro, Sureste y Suroeste. }\end{array}$ & \\
\hline 2014 & $\begin{array}{l}\text { Publicación del Acuerdo que establece la Circunscripción Territorial de } \\
\text { Delegaciones Regionales de la SECTUR. }\end{array}$ & \\
\hline 2015 & $\begin{array}{l}\text { Publicación del Reglamento de la Ley General de Turismo; el CPTM registra } \\
23 \text { oficinas en el extranjero. }\end{array}$ & \\
\hline
\end{tabular}

Fuente: elaborado con base en DO, 1937; DOF, 2014; DOF, 2015; FCE y SECTUR, 2006.

Jiménez (1993) documenta construcciones viales importantes que facilitaron la interrelaciones socioeconómicas de la Ciudad de México con el resto del país: entre 1920 y 1930, quedó enlazada, por vía carretera, con Laredo (cruce fronterizo con Estados Unidos), Pachuca y Toluca (periferia cercana a la capital mexicana), Morelia-Uruapan, Guadalajara (centro y occidente del país), Acapulco (puerto del Pacífico), Puebla- Tehuacán- Fortín de la Flores-Córdoba-Veracruz (hacia el este y la costa del Golfo de México) y Puebla-Oaxaca (carretera hacia el este y continuidad hacia el sur). Esta selección de lugares facilitó la conectividad terrestre no sólo con los destinos referidos, que años después fungirían como receptores importantes de turistas, sino con otros que yacían en la cercanía de los ejes trazados en los segmentos del trayecto o en la continuidad de las localidades conectadas; ejemplos son los de Acapulco, enlazado, años más tarde, por un eje costero con ramales hacia el sureste (Bahía de Huatulco) y el noroeste (Zihuatanejo) y Mérida que se conecta con Progreso y Chichén Itzá (Ibid.); en este escenario, aparecen los primeros registros de cantidad de turistas (Tabla 1).

Otro conjunto importante de localidades son favorecidas por el desarrollo vertiginoso de los enlaces aéreos, entre 1928 y 1929; aparecen «...rutas aéreas que ligan diversas ciudades, entre ellas: México-Matamoros con su ramal Tampico-Tuxpan, MatamorosMazatlán, Tejería-Mérida y otras ciudades como Tapachula, Tijuana, Veracruz, Minatitlán, Villahermosa, Campeche y Mérida» (Jiménez, op. cit.: 16-17). Algunos de estos lugares, que formaron parte de un escenario primigenio de influencia geográfica de la capital por vía aérea, se revelan, en el presente, como destinos turísticos reconocidos (Figura 1). 
La selección sucesiva de destinos turísticos, en la perspectiva histórica, fue documentada esencialmente con base en la identificación de acontecimientos socioeconómicos relevantes y el reconocimiento de intervenciones significativas de actores gubernamentales.

Los años treinta, del siglo XX, tuvieron una impronta geográfica en la actividad turística: se van acomodando estructuras gubernamentales especializadas en la atención y desarrollo del turismo nacional; asimismo, se delimitan las primeras zonas de interés turístico (Tabla 1); también, este escenario se beneficia mediante la inauguración de nuevas rutas aéreas, con las intervenciones centrales de Pan Am y la Compañía Mexicana de Aviación, como México-La Habana en 1931 y México-Los Ángeles, MéxicoMérida-Chetumal y México-Monterrey-Laredo en 1937. Este hecho marca el inicio de un proceso expansivo de selectividad territorial hacia lugares del interior y del exterior del país; hoy en día, éstos continúan operando como enlaces turísticos de primer orden.

Durante los años cuarenta, se remarcan lugares ya seleccionados con nuevos atributos administrativos y aparecen otros que indican la fuerte campaña de promoción turística de México en Estados Unidos, en particular: se declaran, como aeropuertos internacionales, los de la Ciudad de México, Mérida, Tapachula, Nuevo Laredo, Tampico y Hermosillo y se abren delegaciones foráneas de turismo en Nueva York, San Antonio, Los Ángeles y Tucson. A pesar del movimiento errático de las estadísticas de cantidad de turistas (133 200 en 1940; 173100 en 1941; 97800 en 1942; 133600 en 1943; 126200 en 1944), debido a la Segunda Guerra Mundial, se afirma que fue un decenio con un ambiente interno favorable para el turismo, debido a creación de la Asociación Mexicana de Hoteles y Moteles, en 1942, y la Asociación de Agencias de Viajes en 1945. Esta plataforma organizativa doméstica marca el reacomodo interno del país que entra en pleno apogeo en el periodo post-bélico; se considera que el despegue del turismo moderno en México aconteció en este lapso temporal (Jiménez, op. cit.); en este escenario, el turismo nacional se beneficia de un contexto socioeconómico boyante de Estados Unidos. Hacia finales de esa década, los lugares seleccionados para el turismo se ven favorecidos por la declaratoria del presidente en turno que exhibe a la "industria turística" como un renglón de ingresos cuantiosos en la balanza de pagos y, por tanto, de relevancia para la política prevaleciente de sustitución de importaciones (Tabla 1); en la práctica, lo que se benefició esencialmente fue la promoción y el desarrollo del turismo internacional y las facilidades de los viajeros en cuanto a la accesibilidad geográfica de los destinos turísticos (Madrid, 2014).

Los años cincuenta y sesenta, del siglo $\mathrm{XX}$, atestiguan la expansión del turismo mexicano tanto en lo referente a la consolidación de la planta hotelera y el acceso geográfico de los destinos, como en lo que concierne a la intensificación de la promoción internacional. No fueron casuales los lugares elegidos por los presidentes sucesivos en turno (Ruiz Cortínez, Adolfo López Mateos y Gustavo Díaz Ordaz) en sus campañas presidenciales; en sus discursos, se refirieron a otros lugares para ilustrar los rasgos que debería poseer la actividad turística nacional (DOF, 2014); este contexto político favoreció a Acapulco, principal centro turístico del país en ese entonces, Tijuana, Mexicali, Ensenada, Mérida, Cozumel y Cuernavaca. Los acontecimientos ligados con los nuevos acuerdos de transportación aérea con Francia y Países Bajos, entre 1950 y 1955, también 
incentivaron el arribo de turistas europeos que eligieron Air France y KLM como opción de transportación hacia México. La cantidad de turistas registrados pasa de 261000 en 1948 a 697000 en 1958.

El patrón territorial entre estos dos decenios cambia a favor de los destinos de playa; en la década de 1950, la atencióm aún se centraba en los lugares turísticos con intereses culturales del interior como la Ciudad de México, Oaxaca, Guanajuato y los de la Península de Yucatán, aunque se destacaba ya el carácter excepcional de tres centros (Acapulco y Veracruz, costeros, y Tijuana, fronterizo) que acapararon la atención selectiva de agentes sociales nacionales y extranjeros. Por otra parte, el Plan Nacional de 1963 (Tabla 1) señala la incorporación de nuevos lugares en donde se favoreció la creación y fortalecimiento de obras públicas (agua potable, alumbrado y pavimentación); se trata de sitios localizados en las costas mexicanas y la frontera con Estados Unidos entre los que destacan Mazatlán, Guaymas, Veracruz, Acapulco, Manzanillo, Ciudad Juárez, Progreso, Nuevo Laredo, Puerto Vallarta y Tijuana (Figura 1). La actividad turística amplió su cobertura y articulación macro-regional al considerar la creación de carreteras y la construcción de terminales de ómnibus; además de las localidades señaladas con antelación, aparecen otras, hoy turísticas también, que son capitales estatales donde se han mejorado o acondicionado sus aeropuertos de carácter federal; son los casos de Saltillo, Zacatecas, Guadalajara, Campeche, Chetumal, Colima, Aguascalientes, Villahermosa, Chihuahua, Monterrey, Tepic, San Luis Potosí y Culiacán. Asimismo, se benefician otros destinos de importancia micro-regional como Cozumel, Isla Mujeres, Palenque, Pátzcuaro, Uruapan y León (Jiménez, op. cit.; Propin y Sánchez, 2002); en el decenio de los sesentas, se fortaleció la imagen turística de México en el mundo: se relacionan acontecimientos como la promoción de las quince delegaciones del Departamento de Turismo en el extranjero (doce en Estados Unidos, dos en Canadá y una en Buenos Aires) y el impacto publicitario de los XIX Juegos Olímpicos de 1968 (DOF, 2014; Jiménez, op. cit.).

La década de 1970 fue decisiva en la consolidación del calificado «turismo moderno en México» como escenario que dio paso, en 1983, a «la etapa del neoliberalismo» cuando la actividad turística desempeñó un lugar destacado en las reestructuraciones económicas del país (Ibid.: 105). La creación de la Secretaría de Turismo (SECTUR), la publicación de la Ley Federal al Turismo y, en particular, la formación del Fondo Nacional de Fomento al Turismo (FONATUR) fueron hechos relevantes que se relacionan con el origen de los denominados «Centros Integralmente Planeados» (Castro, 2007: 3; DOF, 1996: 8): el carácter selectivo de los cinco destinos iniciales (Cancún, Los Cabos, Bahías de Huatulco, Ixtapa-Zihuatanejo y Loreto-Nopoló) pervive, en particular, en los dos primeros que se han erigido como lugares «dinámicos con preferencia del turismo extranjero» (De Sicilia, 2000; Propin y Sánchez, 2007: 157).

Hasta el presente, se han sucedido reestructuraciones internas y declaratorias diversas encaminadas al fortalecimiento del sector dentro de la economía mexicana y a la consolidación de la imagen turística del país. Entre algunos de los hechos significativos están la constitución del Consejo de Promoción Turística de México (CPTM), como «empresa de participación estatal mayoritaria» (FCE y SECTUR, 2006: 49) en 1999 y la publicación en el Diario Oficial de la Federación, en 2014, del Acuerdo que establece 
la Circunscripción Territorial de Delegaciones Regionales de la SECTUR (Tabla 1). En este contexto, las sucesiones presidenciales han atestiguado informaciones diversas que señalan, por una parte, la marca identitaria de «El Turismo, la alternativa de México» (SECTUR, 2007) y, por la otra, la selección de centros o regiones para alentar el desarrollo turístico: por ejemplo, durante la administración de Ernesto Zedillo (1994-2000), se declararon acciones prioritarias selectivas, en el orden territorial, que priorizaron:

«...los destinos turísticos de playa, incluyendo los cinco centros turísticos integralmente planeados por FONATUR y los siete destinos de playa tradicionales más importantes [Acapulco, Cozumel, La Paz, Manzanillo, Mazatlán, Puerto Vallarta y Veracruz]; a la frontera norte del país...; a las grandes ciudades de México, Guadalajara y Monterrey y al desarrollo de una nueva oferta en las Barrancas de la Sierra Tarahumara de Chihuahua, en el Mundo Maya del sureste de México y en parques naturales y áreas naturales protegidas seleccionadas... además de continuar la promoción regional del grupo de ciudades coloniales» (DOF, 1996: 15).

La creación y puesta en marcha del Programa de Pueblos Mágicos cambió la geografía turística del país; el crecimiento notorio de lugares seleccionados y aprobados con esa categoría densificó la oferta y movilidad interna de los turistas nacionales y extranjeros (Chávez y Rosales, 2015; SECTUR, 2014).

El reglamento de la Ley General de Turismo, publicado el 6 de julio de 2015, aunque no señala explícitamente el carácter selectivo de lugares, marca pautas territoriales relevantes para el desarrollo turístico inmediato: precisa bases para la colaboración y coordinación entre los tres órdenes de gobierno (federal, estatal, municipal) para impulsar y promover el turismo; enfatiza la importancia estratégica del Atlas Turístico de México y señala la necesidad de identificar las regiones turísticas y las zonas de desarrollo sustentable, actuales y potenciales (DOF, 2015). Previo a este escenario, en 2013, el presidente Enrique Peña Nieto, anuncia la selección de 44 destinos turísticos que califica como principales para elaborar sus Agendas de Competitividad (Tabla 2); éstas tienen por objetivos, entre otros, «promover un mayor flujo de turistas e inversiones, a fin de convertir la actividad turística en una palanca de desarrollo económico y generadora de empleos, que beneficie a las regiones del país; potencializar los atractivos que ofrecen; diversificar e innovar la oferta de productos y consolidar destinos; posicionar a México como un destino atractivo en segmentos poco desarrollados, como el turismo cultural, ecoturismo y aventura, salud, deportes, de lujo, de negocios y reuniones, y religioso» (SECTUR, 2013: 1).

Sin embargo, los datos estadísticos de la SECTUR, para el mismo año 2013, no incluyen a cuatro de los destinos seleccionados para la elaboración de sus respectivas agendas: Chalma, San Juan de los Lagos y Tlacotalpan, clasificados como «lugares sagrados católicos con magnetismo espiritual» (Propin y Sánchez, 2015) e Ixtapan de la Sal, reconocido por sus balnearios de aguas termales; esto induce a considerar que segmentos del mercado turístico, como el religioso y el de salud, comienzan a ser valorados como opciones propiciadoras de la diversificación de la oferta turística del país. 


\section{Tabla 2 \\ MÉXICO: DESTINOS TURÍSTICOS SELECCIONADOS PARA ELABORAR AGENDAS DE COMPETITIVIDAD EN 2013}

\begin{tabular}{|l|l|l|l|}
\hline \multicolumn{4}{|c|}{44 destinos turísticos, calificados oficialmente como «principales», en 2013} \\
\hline 1. Acapulco & 12. Guadalajara & 23. Morelia & 34. San Miguel de Allende \\
\hline 2. Aguascalientes & 13. Guanajuato & 24. Monterrey & 35. Tampico-Madero \\
\hline 3. Ciudad Juárez & 14. Hermosillo & 25. Riviera Nayarit & 36. Tijuana \\
\hline 4. Campeche & 15. Huatulco & 26. Oaxaca & 37. Tlacotalpan \\
\hline 5. Cancún & 16. Ixtapa-Zihuatanejo & 27. Pachuca & 38. Tlaxcala \\
\hline 6. Chalma & 17. Ixtapan de la Sal & 28. Puebla & 39. Torreón \\
\hline 7. Ciudad de México & 18. León & 29. Puerto Vallarta & 40. Tuxtla Gutiérrez \\
\hline 8. Cozumel & 19. Los Cabos & 30. Querétaro & 41. Veracruz-Boca del Río \\
\hline 9. Cuernavaca & 20. Manzanillo & 31. Riviera Maya & 42. Villahermosa \\
\hline 10. Durango & 21. Mazatlán & $\begin{array}{l}\text { 32. San Juan de los } \\
\text { Lagos }\end{array}$ & 43. Xalapa \\
\hline 11. Ensenada & 22. Mérida & 33. San Luis Potosí & 44. Zacatecas \\
\hline
\end{tabular}

Nota: las celdas resaltadas distinguen a los destinos turísticos con ofertas distintas a las de sol y playa.

Fuente: elaborado con base en SECTUR, 2013.

\section{METODOLOGÍA}

Las estadísticas disponibles representan indicios tangibles del proceso de selectividad de los destinos turísticos: en el sentido temático-metodológico, son restrictivas ya que condicionan el contenido de los indicadores para caracterizar y clasificar los lugares; en lo investigativo, informan de las priorizaciones territoriales señaladas en las políticas sectoriales de fomento turístico.

Las cifras oficiales especializadas publicadas por la Secretaría de Turismo (DATATUR), seriadas anualmente, representan la plataforma estadística esencial de este trabajo. Con base en la fuente citada y en otras referencias bibliográficas, se compiló y comparó información de los destinos turísticos entre 1974 y 2013 (Tabla 3); los cortes temporales realizados indican acontecimientos relevantes en el acontecer del turismo en el país: origen de la Secretaría de Turismo (1974); disposición de las estadísticas en formato digital (1992); cambio relevante en el partido político que llega a Presidencia (2000); nueva restructuración político-gubernamental (2010). El análisis comparativo temporal entre la cantidad de destinos turísticos, de acuerdo con su localización geográfica costera, interior o fronteriza, reveló comportamientos territoriales específicos.

La extensión superficial del país y su historia colonial intervienen sobre el predominio de destinos turísticos localizados al interior del territorio nacional; por ello, aquellos asociados con los sitios arqueológicos y el patrimonio cultural tangible e intangible, yacentes 
en asentamientos humanos con tamaños poblacionales disímiles, poseen una distribución regional extendida que aglutina, incluso en el presente, a más de la mitad (59\%) de los lugares registrados en las bases de datos. Sin embargo, tales sitios no han sido los más favorecidos en cuanto a inversiones hoteleras; la selección territorial de destinos turísticos, asociadas con la intervención de agentes sociales diversos, ha deparado en un incremento significativo del alojamiento turístico en los destinos costeros que representan casi la tercera parte del total de lugares (34\% en 2013) y concentran cerca de la mitad (49\%) de los cuartos disponibles en el país. En esta comparación, la Ciudad de México, localizada en el interior, registra la mayor cantidad de cuartos (47 911 en 2013); seguido de cerca por otros destinos costeros, que se desarrollaron a finales del siglo pasado, como Cancún (30 183 cuartos) o en los últimos quince años como la Riviera Maya (35 721); estos dos últimos, poseen mayor disponibilidad de cuartos que el conjunto registrado en las dos ciudades más pobladas del país después de la Ciudad de México: Guadalajara (18 046) y Monterrey (12 018).

\section{Tabla 3}

MÉXICO: CARACTERÍSTICAS ESPACIO-TEMPORALES DE DESTINOS TURÍSTICOS

\begin{tabular}{|c|c|c|c|c|c|c|c|c|c|c|}
\hline \multirow{3}{*}{$\begin{array}{l}\text { Ubicación } \\
\text { regional }\end{array}$} & \multicolumn{8}{|c|}{ Destinos turísticos } & \multirow{2}{*}{\multicolumn{2}{|c|}{$\begin{array}{c}\text { Cuartos } \\
2013\end{array}$}} \\
\hline & \multicolumn{2}{|c|}{ 1974-1975 } & \multicolumn{2}{|c|}{ 1992-1999 } & \multicolumn{2}{|c|}{ 2000-2009 } & \multicolumn{2}{|c|}{$2010-2013$} & & \\
\hline & Cantidad & $\%$ & Cantidad & $\%$ & Cantidad & $\%$ & Cantidad & $\%$ & Cantidad & $\%$ \\
\hline Interior & 9 & 47 & 30 & 57 & 40 & 58 & 51 & 59 & 177235 & 47 \\
\hline Costa & 8 & 42 & 19 & 36 & 24 & 35 & 29 & 34 & 181542 & 49 \\
\hline Frontera & 2 & 11 & 4 & 7 & 5 & 7 & 6 & 7 & 14209 & 4 \\
\hline Total & 19 & 100 & 53 & 100 & 69 & 100 & 86 & 100 & 372986 & 100 \\
\hline
\end{tabular}

Fuente: elaborado con base en DATATUR, 2011,2014, 2015 y 2015a; Müller y Susewind, 1977.

Los destinos turísticos, seleccionados en los registros documentales y estadísticos, aumentaron en cantidad y cobertura territorial en casi cuarenta años; aquellos primeros del decenio de los setentas continúan mostrando indicios de selectividad territorial diversa, a pesar del auge vertiginoso de otros creados con posterioridad como Cancún y Los Cabos (Figura 1). Sin embargo, circunstancias sociales diversas intervienen sobre su reconocimiento estadístico; ejemplo de ello es lo que acontece en el estado de Tamaulipas, en la porción norte-oriental del país; el vacío informativo, que se refleja en la Figura 1, no significa la ausencia de lugares turísticos de importancia regional; la ciudad fronteriza de Reynosa, que aparecía en los registros estadísticos (Propin y Sánchez, 2002 y 2007), no es excluida en los datos a partir de 2000, período en el que se recrudece la inseguridad social, ligada con el narcotráfico, en esta entidad político-administrativa.

La exploración de las estadísticas disponibles en 2013 (DATATUR, 2014), con el propósito de identificar indicadores que facilitaran diferenciar los niveles de selectividad territorial de los destinos turísticos, se realizó en los tres pasos metodológicos siguientes: 


\section{Figura 1 \\ MÉXICO: SELECTIVIDAD TERRITORIAL DE DESTINOS TURÍSTICOS EN 1975 Y 2013}

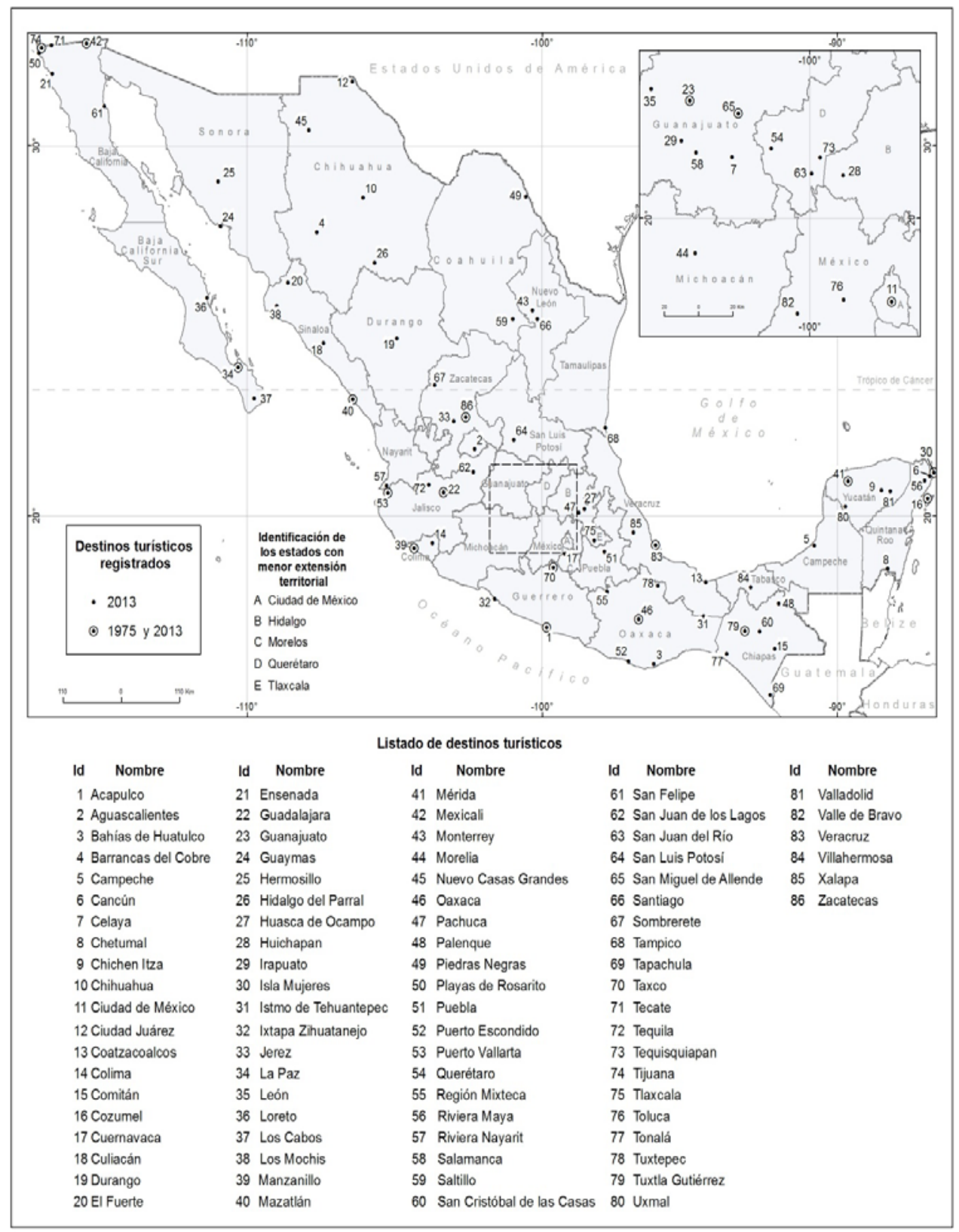

Fuente: elaborado con base en DATATUR, 2014; Müller y Susewind, 1977. 
a. Exploración inicial de las series de datos.

Las cifras absolutas, de frecuente utilización, de cantidad total de cuartos disponibles y de turistas, no permitieron identificar diferencias específicas relacionadas con la selectividad territorial (Figura 2); la muy alta correlación estadística entre ambas variables (0.9) indicó esencialmente la alternativa de realizar jerarquización de los destinos turísticos que no satisfacía los intereses de este trabajo. Sin embargo, las cifras relativas, relacionadas con las proporciones porcentuales de turistas extranjeros y de cuartos en hoteles de mayor categoría turística, facilitaron visualizar una dispersión estadística de destinos que emergió como escenario investigativo propicio para el fin perseguido (Figura 3).

\section{Figura 2 \\ MÉXICO: CORRELACIÓN DE CIFRAS ABSOLUTAS DE LOS DESTINOS TURÍSTICOS, 2013}

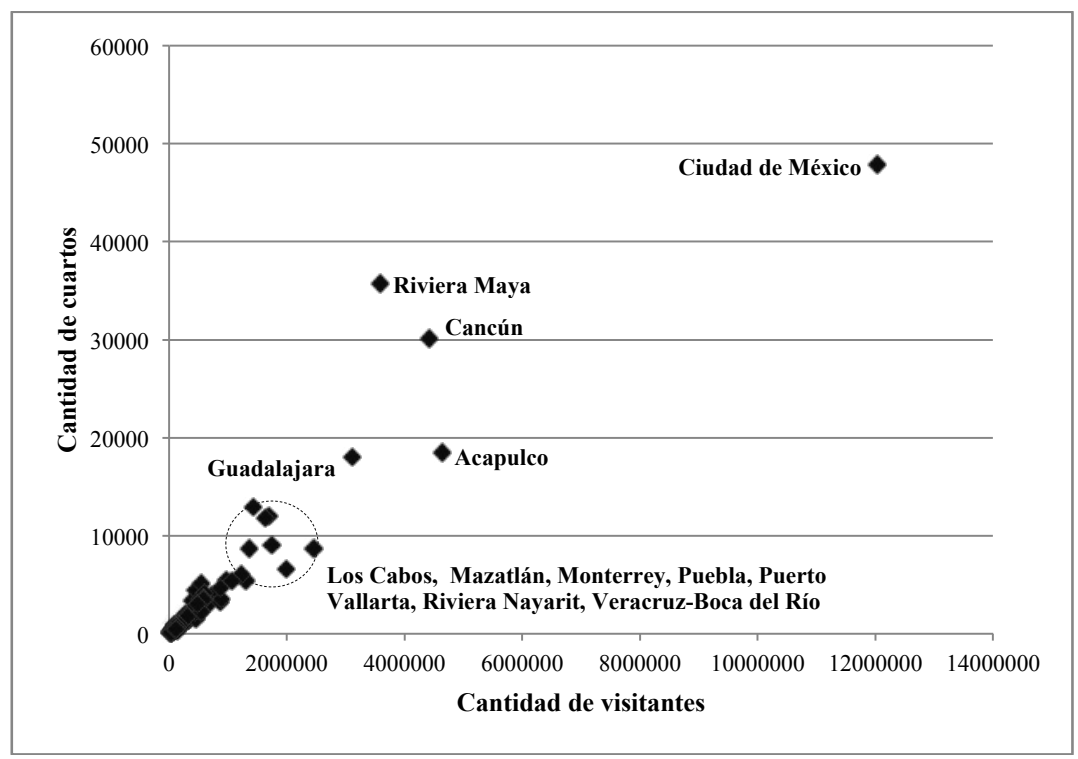

Fuente: elaborado con base en DATATUR, 2014.

\section{b. Identificación de los indicadores}

Con base en el análisis anterior y, esencialmente, en los datos oficiales disponibles se conformaron tres indicadores relacionados con la selectividad territorial que se describen a continuación:

Indicador 1. Exclusividad del destino turístico (EDT)

Esta medición se asumió como indicio de las intervenciones selectivas de agentes promotores e inversionistas en cuanto a la exclusividad del destino turístico. 


$$
\mathrm{EDT}=\mathrm{CHC} / \mathrm{CH} .100 \%
$$

CHC: cantidad de cuartos en hoteles de cinco estrellas

$\mathrm{CH}$ : cantidad total de cuartos

Figura 3

MÉXICO: CORRELACIÓN DE CIFRAS

RELATIVAS DE LOS DESTINOS TURÍSTICOS, 2013

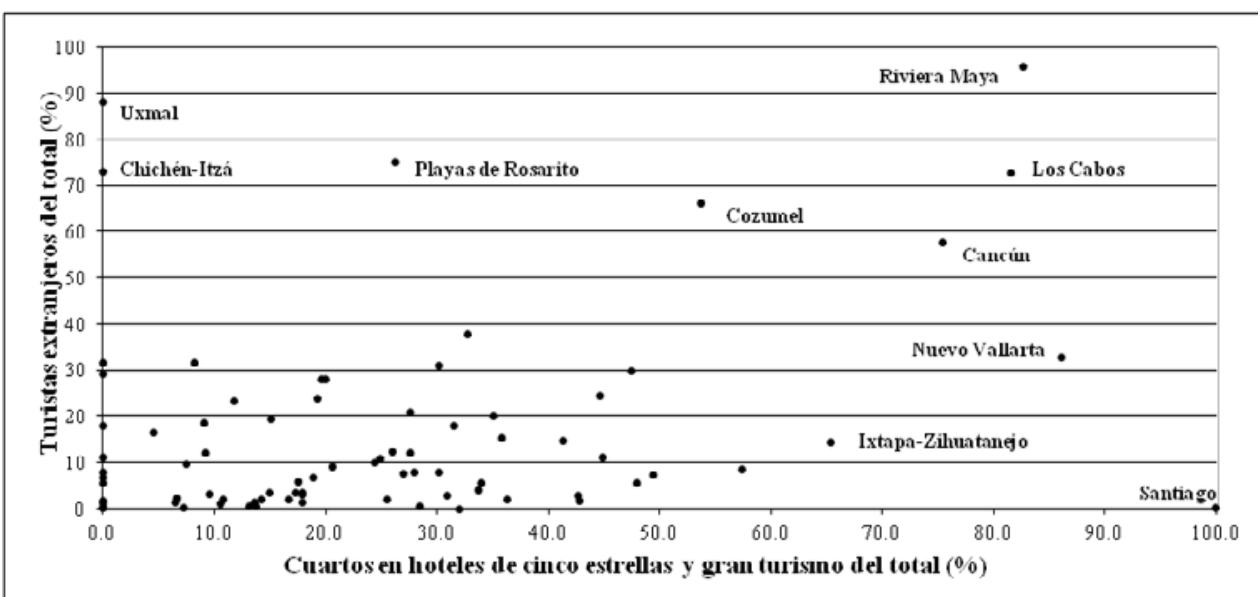

Fuente: elaborado con base en DATATUR, 2014.

A continuación, la averiguación se enfocó hacia las mediciones de la selectividad territorial de los turistas extranjeros como expresiones que revelan la imagen internacional y la elección selectiva foránea del destino; en este sentido, se conformaron los dos indicadores siguientes:

Indicador 2. Afluencia de turistas extranjeros (ATE)

$$
\mathrm{ATE}=\mathrm{CTE} / \mathrm{CTT} .100 \%
$$

CTE: cantidad de turistas extranjeros

CTT: cantidad total de turistas

Indicador 3. Pernocta predominante de turistas extranjeros (PPTE)

PPTE [se identificó cuando] CNTE $>$ CNTN 
CNTE: cantidad de noches promedio de turistas extranjeros

CNTN: cantidad de noches promedio de turistas nacionales

\section{c. Clasificación de los destinos turísticos}

Los 86 destinos turísticos considerados se valoran como selectivos en el sentido de ser los registrados en las estadísticas oficiales; existen otros que aún no forman parte de las cifras nacionales. Sin embargo, este conjunto de lugares, como es de esperar, detenta comportamientos turísticos disímiles; en este escenario, los destinos turísticos, en sus similitudes y diferencias, se estratificaron, en forma jerárquica, en niveles de selectividad territorial. Para lograr tal finalidad, los datos se procesaron mediante procedimientos generalizados del método de tipificación probabilística (Thürmer, 1983; Propin, 2003).

a. Ponderación de los indicadores seleccionados.

Los valores resultantes de los tres indicadores seleccionados se clasificaron en tres rangos (Tabla 4).

\section{Tabla 4 \\ MÉXICO: RANGOS ESTABLECIDOS EN LOS INDICADORES SELECCIONADOS}

\begin{tabular}{|l|c|c|c|}
\hline \multirow{2}{*}{ Cualitativos } & \multicolumn{3}{|c|}{ Cuantitativos } \\
\cline { 2 - 4 } & EDT (\%) & ATE (\%) & PPTE (\# de noches) \\
\hline 3- Alto & $>50$ & $>50$ & $>5$ \\
\hline 2- Medio & $30-50$ & $30-50$ & $2-5$ \\
\hline 1- Bajo & $<30$ & $<30$ & $1-2$ \\
\hline
\end{tabular}

Fuente: elaborado con base en SECTUR, 2014.

b. Identificación de códigos y de nubes tipológicas y elaboración del mapa temático resultante

Los destinos turísticos fueron codificados de acuerdo con el comportamiento cuantitativo generalizado de cada indicador y se agruparon por la identidad de los códigos (Tabla 5); los casos atípicos fueron incluidos en algún grupo por la similitud de códigos que se asume como la variación de un indicador en un sólo rango; este último escenario caracterizó a una cantidad reducida de destinos (Tabla 5).

La leyenda del mapa resultante (Figura 4) posee dos distinciones temáticas: por una parte, adiciona el criterio del tamaño del destino turístico de acuerdo con la afluencia total de turistas como información interpretativa territorial y, por la otra, sustituye los valores ponderados por los rangos cuantitativos de cada indicador para facilitar las descripciones regionales de los niveles revelados. 
Tabla 5

\section{IDENTIFICACIÓN DE LOS NIVELES DE SELECTIVIDAD TERRITORIAL MEDIANTE LA CODIFICACIÓN Y AGRUPACIÓN DE CÓDIGOS}

\begin{tabular}{|c|c|c|c|c|}
\hline \multirow{2}{*}{ Nivel } & \multicolumn{2}{|c|}{ Indicadores ponderados } & \multirow{2}{*}{ \# de destinos } \\
\cline { 2 - 5 } & EDT & ATE & PPTE & 18 \\
\hline \multirow{2}{*}{ I } & 1 & 1 & $*$ & 24 \\
& 1 & 1 & 1 & 3 \\
\hline III & 1 & 1 & 2 & 10 \\
\hline IV & 1 & 1 & 3 & 1 \\
\hline \multirow{2}{*}{ V } & 2 & 1 & $*$ & 2 \\
\hline \multirow{2}{*}{ VI } & 2 & 1 & 2 & 7 \\
\hline VII & 3 & 1 & 1 & 1 \\
\hline VIII & 3 & 1 & 3 & 1 \\
\hline IX & 3 & 3 & 2 & 2 \\
\hline X & 3 & 3 & 2 & 3 \\
\hline & & 1 & 3 & 2 \\
\hline
\end{tabular}

* Destinos con pernocta predominante de turistas nacionales Fuente: elaborado con base en SECTUR, 2014; Tabla 4.

\section{HALLAZGOS INVESTIGATIVOS}

Los diez niveles de selectividad territorial de los destinos turísticos en México revelan localizaciones regionales disímiles y comportamientos funcionales contrastantes (Figura 4; Tabla 6).

Son notorias las desproporciones relativas entre los niveles inferiores (I y II) y superiores (IX y X) de la clasificación realizada; los primeros, que representan a más de la mitad $(52 \%)$ de los destinos turísticos del total nacional, reúnen a fracciones reducidas de los porcentajes de turistas extranjeros $(14.1 \%)$ y de cuartos en hoteles de mayor categoría (12\%); sin embargo, los lugares más selectos (niveles IX y X), con menor presencia (sólo cinco de los 86 registrados), aúnan a más de la mitad de los 
turistas extranjeros que arriban al país (54\%) y al $43.5 \%$ de los cuartos en hoteles de cinco estrellas; esto es indicativo del resultado de las políticas turístico-territoriales que han privilegiado la habilitación turística y, como parte de ésta, la presencia notable de grupos hoteleros de primera importancia internacional. Unido a ello, se revelan también los valores más altos de pernocta de los foráneos con más de cinco noches de permanencia en los destinos clasificados en el nivel X; por el contrario, los inferiores se destacan por la pernocta de turistas nacionales o sólo de una o dos noches de los extranjeros (Tabla 5).

Los niveles intermedios (IV, V, VI) exhiben características estadísticas contradictorias de interés singular: el IV, con sólo dos casos, reúne una reducida proporción de turistas foráneos del total nacional; sin embargo, éstos predominan por sobre los nacionales aunque los últimos son los de pernocta mayoritaria (Tabla 5 y 6). Por su parte, los diez destinos del nivel VI detentan a más de la tercera parte de los turistas del total nacional sin que los porcentajes de extranjeros sean relevantes y, además, concentran a casi la cuarta parte de los cuartos en hoteles de mayor categoría.

Los niveles, jerarquizados de menor a mayor selectividad territorial, fueron denominados de acuerdo con los comportamientos cuantitativos de los indicadores seleccionados; a continuación, se sintetizan características regionales particulares de cada uno de ellos.

\subsection{Exclusividad baja con estadía mayoritaria de turistas nacionales}

Los dieciocho destinos turísticos, con menor selectividad territorial, se caracterizan por disponer de los más bajos porcentajes de cuartos en hoteles de mayor categoría y reportar una baja afluencia de turistas extranjeros y una pernocta prevaleciente de nacionales (Figura 4); estos lugares poseen una contextualización regional heterogénea. Los casos de Tecate, Sombrerete, Tequisquiapan y Huasca de Ocampo son una proporción reducida de los 83 "Pueblos Mágicos"; esta denominación responde a un programa del gobierno federal relacionado con la rehabilitación y promoción de lugares que, seleccionados por los gobiernos estatales, llegan a ser inscritos en él. Los destinos turísticos restantes de este nivel combinan, en mayor o menor medida, recursos turísticos naturales y culturales que representan opciones locales para la movilidad de turistas, esencialmente, nacionales. Es pertinente señalar que la presencia predominante de hoteles de categoría baja y media en estos destinos no se relaciona con su alcance regional en cuanto a la procedencia geográfica de los turistas; algunos como Tijuana (en la frontera norte, con cantidades notorias de visitantes estadounidenses), San Juan de los Lagos (segundo santuario católico más visitado del país) y Barrancas del Cobre (centrado en sus paisajes naturales singulares) poseen áreas de influencia turística que rebasan los límites nacionales. Los destinos turísticos de este grupo, con menores cantidades de turistas, exhiben un patrón territorial disperso (Figura 4); en general, representan nuevas ofertas en el sur del país u opciones a visitar desde lugares de anclaje (en cuanto a pernocta) clasificados en niveles superiores que se localizan en el centro y norte de México. 
Figura 4

MÉXICO: NIVELES DE SELECTIVIDAD TERRITORIAL EN LOS DESTINOS TURÍSTICOS

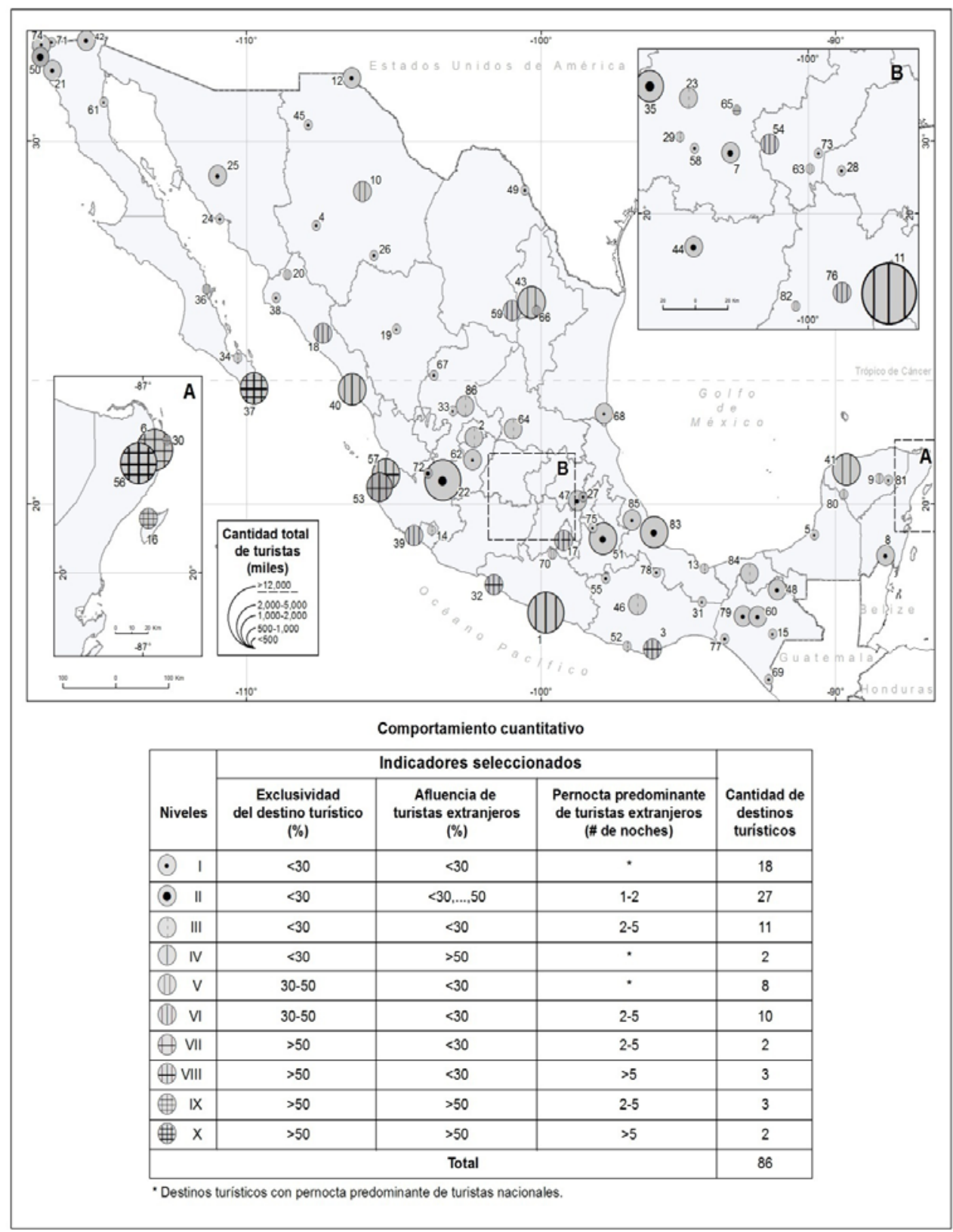

Fuente: elaborado con base en SECTUR, 2014; Tabla 5. 
Tabla 6

PROPORCIONES RELATIVAS DE ATRIBUTOS TEMÁTICOS SELECCIONADOS POR NIVELES REVELADOS

\begin{tabular}{|c|c|c|c|c|c|c|}
\hline \multirow{2}{*}{ Niveles } & \multicolumn{2}{|c|}{ Destinos turísticos } & \multicolumn{2}{c|}{ Turistas (\%) } & \multicolumn{2}{c|}{ Cuartos (\%) } \\
\cline { 2 - 7 } & $\mathbf{N}^{\circ}$ & $\mathbf{\%}$ & Total & $\begin{array}{c}\text { Extranje- } \\
\text { ros }\end{array}$ & Total & 5 estrellas \\
\hline I & 18 & 21 & 7.3 & 3.2 & 6.3 & 2.4 \\
\hline II & 27 & 31 & 25.2 & 10.9 & 21.4 & 9.6 \\
\hline III & 11 & 13 & 7.4 & 2.2 & 8.4 & 3.1 \\
\hline IV & 2 & 2 & 0.1 & 0.4 & 0.1 & 0.0 \\
\hline V & 8 & 9 & 5.2 & 4.0 & 6.8 & 7.1 \\
\hline VI & 10 & 12 & 33.3 & 19.4 & 26.1 & 22.5 \\
\hline VII & 2 & 2 & 2.9 & 2.9 & 3.7 & 4.7 \\
\hline VIII & 3 & 3 & 3.4 & 3.0 & 4.6 & 7.1 \\
\hline IX & 3 & 3 & 7.7 & 22.3 & 9.6 & 17.0 \\
\hline X & 2 & 2 & 7.5 & 31.7 & 13.0 & 26.5 \\
\hline México & $\mathbf{8 6}$ & $\mathbf{1 0 0}$ & $\mathbf{1 0 0}$ & $\mathbf{1 0 0}$ & $\mathbf{1 0 0}$ & $\mathbf{1 0 0}$ \\
\hline
\end{tabular}

Fuente: elaborado con base en SECTUR, 2014; Tabla 5.

\subsection{Exclusividad baja con estadía reducida de turistas extranjeros}

Este nivel reúne la mayor cantidad de destinos del país (27); éstos ocupan un escalón superior en la jerarquía debido a la mayor afluencia y pernocta de turistas extranjeros (Figura 4). Estos atributos característicos se manifiestan en contextos locales diversos; junto a destinos que fungen como capitales estatales del norte, centro y este del país (Mexicali, Hermosillo, Durango, Guadalajara, Morelia, Pachuca, Puebla, Tlaxcala, Veracruz-Boca del Río, Tuxtla Gutiérrez, Campeche y Chetumal), en su mayoría reconocidas por su actividad turística en investigaciones antecedentes (Propin y Sánchez, 2002 y 2007), aparecen otros como algunos de los denominados Pueblos Mágicos (Comitán, Jerez, San Cristóbal de las Casas, Tequila y Valladolid). Los restantes son ciudades distribuidas hacia diferentes puntos cardinales del territorio: Ensenada, Ciudad Juárez, Los Mochis, León, Salamanca, Celaya (estos tres últimos muy próximos unos a otros en el centro de México) y Tehuantepec en el sur. Se añaden tres lugares con génesis turísticas disímiles: el sitio arqueológico de Palenque, el corredor turístico-costero Playas de Rosarito y la misión de San Felipe. Al igual que el nivel anterior, los destinos poseen una localización regional amplia, con la particularidad de una mayor afluencia de turistas en aquellos localizados en la porción central, como Guadalajara, Puebla y Veracruz.

\subsection{Exclusividad baja con estadía relativamente significativa de turistas extranjeros}

La exclusividad del destino y la afluencia de turistas extranjeros son semejantes a los de los niveles precedentes; sin embargo, su distintivo es una mayor pernocta de turistas 
extranjeros. Los once sitios aquí identificados se orientan hacia dos segmentos del mercado turístico: por una parte, el de sol y playa en la costa, tanto del Océano Pacífico (La Paz, Colima, Puerto Escondido) como del Golfo de México (Coatzacoalcos, Villahermosa), son sitios costeros de menor jerarquía que como Acapulco y Cancún; por la otra, el de patrimonio cultural, en ciudades ubicadas, básicamente, en el centro del país (Zacatecas, Aguascalientes, San Luis Potosí, Guanajuato, Irapuato y Oaxaca), exhibe la riqueza arquitectónica derivada, en varios casos, de su pasado minero. Entre los lugares que componen este grupo sobresale la ciudad de Oaxaca por su tradición como centro turístico conocido y promovido, a nivel nacional e internacional, desde hace más de 50 años.

\subsection{Exclusividad baja con afluencia alta de turistas extranjeros de tránsito}

Se identificaron aquí dos sitios arqueológicos importantes de la Península de Yucatán, Uxmal y Chichen Itzá, que cuentan con hoteles pequeños ocupados preferencialmente por turistas nacionales aunque también son visitados por extranjeros interesados en conocer los vestigios de la cultura maya; la afluencia masiva de éstos, aunque en tránsito, representó el criterio esencial para la conformación de este nivel. Se trata de no-nacionales que pernoctan y contratan tours desde sitios turísticos con selectividad territorial superior como Cancún, Riviera Maya y Mérida; tanto Uxmal como Chichén Itzá son lugares complementarios de las rutas ofertadas en la península yucateca, que priorizan los destinos de sol y playa. Los viajes hacia estos dos destinos significan el empleo de un día y con ello, el aumento de las estadías de los turistas en sus lugares de anclaje.

\subsection{Exclusividad intermedia con estadía mayoritaria de turistas nacionales}

Este nivel muestra un aumento en la exclusividad de la planta hotelera aunque con valores bajos de los indicadores referentes a los turistas extranjeros. Se congregan aquí ocho lugares, donde se manifiesta un turismo preferencialmente doméstico que se desarrolla en ámbitos disímbolos: tres capitales estatales muy pobladas (Chihuahua, Monterrey, Mérida), cuatro Pueblos Mágicos de diferente factura (El Fuerte, Santiago, Valle de Bravo y Taxco) y una ciudad relativamente cercana a la capital nacional (San Juan del Río). Algunos de estos sitios fungen como núcleos de intermediación para llegar a otros lugares de interés turístico contenidos en sus propias áreas de influencia; tal es el caso de Chihuahua, con conectividad efectiva hacia el centro y sur del estado del mismo nombre; de Monterrey, que sirve de referencia para llegar a distintos centros de visitación en Nuevo León, y de Mérida, ciudad en la que convergen rutas que promueven la visita a sitios con recursos turísticos variados como cenotes, playas y zonas arqueológicas.

\subsection{Exclusividad intermedia con estadía relativamente significativa de turistas extranjeros}

Los diez destinos turísticos, identificados en este nivel, se caracterizan por concentrar una proporción significativa de cuartos en hoteles de cinco estrellas: aunque predomina la afluencia de turistas nacionales, se reporta una estadía predominante de extranjeros que 
pueden pernoctar hasta cinco noches; se trata de lugares seleccionados para el fomento federal del turismo desde mediados del siglo pasado. En este grupo, sobresalen dos casos: la Ciudad de México, con la mayor entrada al país de turistas nacionales e internacionales a través del aeropuerto internacional Benito Juárez, y Acapulco, destino de acentuada afluencia turística que, nacido en los comienzos de auge del turismo en México a mediados del siglo pasado, se encuentra en el área de influencia próxima de la Ciudad de México, principal emisor de turistas domésticos que arriban al puerto por autopista y vía aérea; ello explica sus muy altas tasas de retorno de turistas que residen en el centro del país. Los destinos restantes, con arribo menor de turistas, se localizan en las cercanías de la Ciudad de México (Cuernavaca, Querétaro y Toluca), en la franja costera del Golfo de California y del Pacífico (Loreto, Culiacán y Manzanillo); Loreto es el único de los originales cinco centros integralmente planeados que aún no ha logrado posicionarse entre los primeros lugares con auge turístico del país.

\subsection{Exclusividad alta con estadía relativamente significativa de turistas extranjeros}

Se agrupan aquí dos destinos turísticos: Puerto Vallarta y San Miguel de Allende (Figura 4). Su selectividad territorial se centra en la proporción importante de cuartos en hoteles cinco estrellas y la presencia importante de turistas extranjeros. El acondicionamiento turístico de estos lugares se halla en función del arribo de visitantes no mexicanos; en este escenario, destaca la conectividad aérea de la terminal de Puerto Vallarta, servida por diversas aerolíneas (Air Canada, Alaska Airlines, American Airlines) que lo enlazan con ciudades de Canadá y Estados Unidos como Toronto, Seattle, San Francisco, Los Ángeles, San Diego y Dallas; los vuelos estacionales de éstas y otras aerolíneas duplican los destinos en ambos países, en temporada alta. Por su parte, San Miguel de Allende, ciudad enlistada en el Patrimonio Cultural de la Humanidad, detenta particularidades que facilitan la conexión con Estados Unidos; es de los pocos destinos en el país que, relativamente cercano a la Ciudad de México, posee un Consulado de ese país; la presencia importante y pernocta de turistas extranjeros se registra en un lugar donde vive una comunidad de residentes jubilados, entre los que predominan los norteamericanos; este escenario se replica en Puerto Vallarta. Ambos destinos turísticos se han reconocido como "paraísos" para pensionados extranjeros, junto a otros, en el mundo, como Algarve, Portugal; Granada, Nicaragua y Cayo Ambergris, Belice.

\subsection{Exclusividad alta y estadía significativa de turistas extranjeros}

En este nivel, quedan incluidos tres destinos de playa, dos de ellos integralmente planeados (Bahías de Huatulco e Ixtapa) y la Riviera Nayarit, ubicados en la costa pacífica mexicana. Se trata de lugares con una importante infraestructura hotelera de categoría superior a la que acuden una cantidad significativa de turistas extranjeros que registran una estadía de más de cinco noches. Su inserción en el mercado turístico, como destinos reconocidos en el ambiente internacional, es relativamente reciente: los años setentas en los dos primeros casos, y apenas en los últimos diez para la Riviera Nayarit. Aunque estos destinos se encuentran en esta categoría alta, no son los más promocionados por el gobierno federal 
en los escenarios internacionales; de hecho, tanto Ixtapa como Riviera Nayarit quedan a la sombra de destinos más conocidos, Acapulco en el primer caso y Puerto Vallarta en el segundo. Huatulco, a pesar de ser uno de los sitios originales integralmente planeados para el turismo desde los años setenta, no ha logrado posicionarse firmemente entre los lugares de preferencia de los visitantes, ni nacionales ni internacionales.

\subsection{Exclusividad alta con estadía relativamente significativa de cantidades impor- tantes de turistas extranjeros}

Este grupo está conformado por tres lugares que tienen una vecindad geográfica entre sí y con la Riviera Maya (destino con mayor jerarquía que éstos y con los que conforma la microrregión turística con mayor relevancia en el país). Tienen un nivel de alta selectividad territorial en sus atributos asociados con la presencia de hoteles de categoría superior y afluencia importante de turistas extranjeros. Cancún es el lugar central del conjunto, que se conecta por vía marítima con las Islas Mujeres y Cozumel (Figura 4); la Riviera Maya constituye una prolongación de la ocupación turística del territorio, cuyo origen se encuentra en Cancún. La conectividad aérea de esta ciudad es notoria con la Ciudad de México y con sitios en América del Norte (Calgary, Montreal, Nueva York, San Francisco, Denver, Salt Lake City, Dallas, Houston, Nueva Orleans), Europa (Londres y Frankfurt, el Caribe (La Habana y Varadero) y el centro y sur de América (San Salvador, Bogotá y Panamá). En particular, Cozumel, principal destino del turismo de cruceros en el Caribe occidental, reporta una notable carga turística debido a la estadía, por unas horas, de cantidades importantes de visitantes (Sánchez y Propin, 2003); la infraestructura básica general de estos tres asentamientos se centra, en su totalidad, en el turismo.

\subsection{Exclusividad alta con estadía significativa de cantidades importantes de turistas extranjeros}

El nivel de mayor selectividad territorial identifica sólo dos destinos: Los Cabos, que emerge en el decenio de los setentas como centro integralmente planeado en el extremo sur de la Península de Baja California, y la Riviera Maya, que constituye un eje turístico costero extendido hacia el sur de Cancún con crecimiento vertiginoso en los últimos quince años (Figura 4). Estos destinos concentran más de la cuarta parte de los turistas extranjeros registrados a nivel nacional y de los cuartos en hoteles de mayor categoría del país (Tabla 6). Ambos poseen enlaces aéreos foráneos; por una parte, Los Cabos tienen vínculos predominantes con Estados Unidos, mediante vuelos bidireccionales con San Diego, Los Ángeles, San Francisco, Dallas, Houston y Phoenix, además de Vancouver, en Canadá; por su parte, el aeropuerto de Cancún es el acceso aéreo principal de los turistas que arriban a la Riviera Maya, con conectividad eficiente hacia Estados Unidos, Canadá, y América Central y del Sur. En particular, la vinculación directa de Los Cabos con la frontera México-Estados Unidos, a través de la carretera transpeninsular, facilita la llegada de una gran cantidad de estadounidenses durante todo el año (Sánchez y Propin, 2012). 


\section{CONCLUSIONES}

La plataforma cognoscitiva, relacionada con la selectividad territorial, es un referente investigativo significativo que permite adentrarse en el escenario actual de competencias entre destinos turísticos; facilita identificar y evaluar aquellos que, por conveniencias e intervenciones de agentes sociales, resultan los más beneficiados en los procesos de inversión y promoción turística.

La expansión territorial del turismo en México, de los últimos dos decenios, ha significado un aumento de la diversificación de la oferta turística, tanto de lugares como de productos, que ha permitido captar segmentos diversos del mercado turístico mundial; este escenario, propicio para el país, ha implicado una diferenciación marcada entre destinos que llegan a complementarse entre sí por la movilidad de los turistas en el territorio nacional.

Los diez niveles de selectividad territorial obtenidos en este estudio informan de la imagen jerárquica actual de los destinos turísticos mexicanos; permiten identificar los centros de mayor exclusividad y manifiestan que la gran cantidad de destinos promovidos actualmente por los gobiernos federal y local no es un reflejo de la consolidación de sitios turísticos al interior del país; en particular, los llamados Pueblos Mágicos, como destinos turísticos nuevos, aún representan opciones incipientes de la voluntad política en favor de la diversificación del mercado turístico nacional. Es evidente que siguen predominando los lugares de sol y playa como preferentes para la inversión y el turismo internacional, tal es el caso de los destinos litorales en la costa noreste de Quintana Roo (Cancún, Riviera Maya) y Los Cabos; otros, que se encuentran en la orla pacífica, están más orientados al mercado interno, como Mazatlán, Manzanillo, Ixtapa, Acapulco, Puerto Escondido y Huatulco, algunos de los cuales han fungido como núcleos turísticos de referencia por más de 50 años, como en el caso de Mazatlán y Acapulco. Al interior del país, es innegable que las capitales estatales tienen una función de intermediación con lugares turísticos de jerarquía inferior, debido a la existencia de infraestructura de alojamiento de clase superior, como en el caso de Guadalajara, Monterrey y la propia capital nacional. Respecto a los núcleos turísticos en las fronteras, sólo Tijuana continúa su trayectoria añeja como destino internacional, aunque las visitaciones sean por unas cuantas horas. Hacia las fronteras del sur, con Guatemala y Belice, los asentamientos poblacionales con actividad turística son prácticamente inexistentes.

\section{BIBLIOGRAFÍA}

ALEXANDROS, A. y JAFARI, J. (2005): «Stated preferences for two Cretan heritage attraction», Annals of Tourism Research, vol. 32, n 4, pp. 985-1005.

CAPECE, G. (2008): Turismo, la esencia del negocio. Buenos Aires, Cengage Learning.

CASTRO ÁLVAREZ, U. (2007): «El turismo como política central de desarrollo y sus repercusiones en el ámbito local: algunas consideraciones referentes al desarrollo de enclaves turísticos en México», en Revista de Investigación en Turismo y Desarrollo Local, vol. 1, n 1. Universidad de Málaga. Disponible en http://www.eumed.net/rev/ turydes/01/uca.htm 
CICCOLELLA, P (1999): «Globalización y dualización en la Región Metropolitana de Buenos Aires. Grandes inversiones y restructuración socioterritorial en los años noventa», Eure (Santiago), vol. 2, n 76, pp. 5-27.

CICCOLELLA, P. (2006): «Economía y espacio: ejes de discusión para un desarrollo territorial más allá de la globalización», en Párrafos Geográficos, vol. 5, n 1 . Universidad Nacional de la Patagonia San Juan Bosco. Disponible en http://igeopat.org/ parrafosgeograficos/

CHÁVEZ BECKER, C. Y ROSALES REYES, T. I. (2015): «El diseño del Programa Pueblos Mágicos desde el enfoque de la gobernanza», en Pueblos mágicos: discursos y realidades. Una mirada desde las políticas públicas y la gobernanza. Ciudad de México, Universidad Autónoma Metropolitana, pp. 23-54.

DATATUR (2011): México: estadísticas actividad hotelera, 1992-2011. México, Secretaría de Turismo. Disponible en http://datatur.sectur.gob.mx/wb/datatur/datatur_usuarios_administracion

DATATUR (2014): México: estadísticas actividad hotelera, 2013. México, Secretaría de Turismo. Disponible en http://datatur.sectur.gob.mx/wb/datatur/datatur_usuarios_ administracion

DATATUR (2015): «Resultados preliminares acumulados a la semana 20». en Sistema Nacional de Información Estadística del Sector turismo de México. México, Secretaría de Turismo. Disponible en http://www.datatur.sectur.gob.mx

DATATUR (2015a): «Resultados de la actividad hotelera en 70 destinos. Diciembre 20122014, Reporte Diciembre», en Sistema Nacional de la información estadística del sector turismo de México. México, Secretaría de Turismo. Disponible en http://www. datatur.sectur.gob.mx

DE SICILIA MUÑOZ, R. A. (2000): «El corredor turístico Loreto-Nopoló-Puerto Escondido, Baja California Sur, en el contexto de los Centros Integralmente Planeados», Cuadernos de Turismo, $\mathrm{n}^{\circ}$ 5, pp. 53-68.

DO (1937): «Reglamento de la Ley General de Población vigente, en su parte relativa a turismo (21-5-1937)», en Diario Oficial, Órgano del Gobierno Constitucional de los Estados Unidos Mexicanos. México, Poder Ejecutivo. Disponible en http://dof.gob.mx/

DOF (1996): «Diagnóstico del mercado turístico mundial y regional. Programa de Desarrollo del Sector Turismo 1995-2000 (27-6-1996)», en Diario Oficial de la Federación, Estados Unidos Mexicanos. México, Secretaría de Turismo. Disponible en http://dof. gob.mx/

DOF (2014): «Manual de Organización General de la Secretaria de Turismo (5-8-2014)», en Diario Oficial de la Federación, Estados Unidos Mexicanos. México, Secretaría de Turismo. Disponible en http://dof.gob.mx/

DOF (2015): «Reglamento de la Ley General de Turismo (6-7-2015)», en Diario Oficial de la Federación, Estados Unidos Mexicanos. México, Secretaría de Turismo. Disponible en http://www.dof.gob.mx/

FCE Y SECTUR (2006): Comportamiento, avances y perspectivas del turismo en México. Colección editorial del Gobierno del Cambio. México, Fondo de Cultura Económica y Secretaría de Turismo. 
FURTADO DA SILVA, L. ET AL. (2012): «Gobernanza y territorialidad en el desarrollo turístico regional. El caso del Oktoberfest en Blumenau-Brasil», Estudios y Perspectivas en Turismo, vol. 21, n 6, pp. 1369-1388.

GÓMEZ LENDE, S. (2010): «Guerra de lugares en Argentina: perspectivas de análisis y ejemplos empíricos», Revista Universitaria de Geografía, vol. 19, n 1, pp. 139-167.

JIMÉNEZ MARTÍNEZ, A. J. (1993): Turismo. Estructura y desarrollo. La estructura funcional del turismo internacional y la política turística de México. Desarrollo histórico. 1945-1990. México, McGraw-Hill.

MADRID FLORES, F. (2014): Realidades y mitos del turismo mexicano. México, CNETUniversidad Anáhuac-LIMUSA.

MÜLLER, B. Y SUSEWIND, B. (1977): «El turismo en México. Aspectos de su diferenciación espacial», en El turismo como factor de desarrollo regional en México. Mainz, Geographisches Institut der Johannes Gutenberg Universität, pp. 13-35.

PROPIN FREJOMIL, E. (2003): Teorías y métodos en Geografía Económica. México, Instituto de Geografía, Universidad Nacional Autónoma de México.

PROPIN FREJOMIL, E. y SÁNCHEZ CRISPÍN, Á. (2002): «La estructura regional del turismo en México», Ería, n ${ }^{\circ}$ 9, pp. 386-394.

PROPIN FREJOMIL, E. y SÁNCHEZ CRISPÍN, Á. (2007): «Tipología de los destinos turísticos preferenciales en México», Cuadernos de Turismo, n 19, pp. 147-166.

PROPIN, FREJOMIL, E. y SÁNCHEZ CRISPÍN, Á. (2015): «Santuarios católicos con magnetismo espiritual en México: una propuesta tipológica», Revista de Geografía Norte Grande, n 61, pp. 91-106.

RAKIĆ, T. y CHAMBERS, D. (2012): «Rethinking the consumption of place», Annals of Tourism Research, vol. 39, $\mathrm{n}^{\circ}$ 3, pp 1612-1633.

REAL ACADEMIA ESPAÑOLA (2014): Diccionario de la lengua española. Edición digital. Disponible en http://lema.rae.es/drae/?val=selectividad

REIG GARCÍA, C. y COENDERS GALLARD, G. (2002): «Segmentación del mercado turístico según las preferencia ambientales», Cuadernos de Turismo, n 9, pp. 123-135.

SÁNCHEZ CRISPÍN, Á. Y PROPIN FREJOMIL, E. (2003): «Dependencias regionales del turismo en la isla de Cozumel», Cuadernos de Turismo, n 11, pp. 169-180.

SÁNCHEZ CRISPÍN, Á. Y PROPIN FREJOMIL, E.(2012): «Transporte y turismo en la península de Baja California, México», Revista Transporte y Territorio, $\mathrm{n}^{\circ}$ 5, pp. 48-71.

SCHWEITZER, P. (2012): «La selectividad territorial, temporal y laboral de la actividad turística: un desafío para las políticas públicas», en Palermo Business Review, n 6. Universidad de Palermo. Disponible en http://www.palermo.edu/economicas/cbrs/ business_review_ed6.html

SECTUR (2007): Programa Sectorial de Turismo 2017-2012. México, Secretaría de Turismo.

SECTUR (2013): «Evalúa Sectur 44 destinos turísticos a través de agendas de competitividad», en Boletín Informativo, $\mathrm{n}^{\circ}$ 143. México, Secretaría de Turismo. Disponible en http://www.ricit.sectur.gob.mx/es_mx/RICIT/Boletin_Informativo

SECTUR (2014): Pueblos Mágicos. México, Secretaría de Turismo. 
SILVA LIRA, I. (2005): «Desarrollo económico local y competitividad territorial en América Latina», en Revista de la Comisión Económica para América Latina, ${ }^{\circ} 85$. CEPAL. Disponible en http://www.eclac.org/publicaciones/xml/5/21045/lcg2266eSilva.pdf

THÜRMER, R. (1983): «Probabilistische Typisierung, Dargestellt am Beispiel der Umlandbedeutung von Zentren in der DDR», Petermanns Geographischen Mitteilungen, $\mathrm{n}^{\circ}$ 2, pp. 89-98.

TRAN, X. y RALSTON, L. (2005): «Tourist preferences influence of unconscious needs», Annals of Tourism Research, vol. 33, n², pp. 424-441. 